\title{
RANS-VOF MODELING OF HYDRODYNAMICS AND SAND TRANSPORT UNDER FULL-SCALE NON-BREAKING AND BREAKING WAVES
}

\author{
A. Fernandez-Mora ${ }^{1}$, J. S. Ribberink ${ }^{2}$, J. van der Zanden ${ }^{3}$, J. J. van der Werf ${ }^{4}$, and N. G. Jacobsen ${ }^{5}$. \\ A 2D RANS-VOF model is used to simulate the flow and sand transport for two different full-scale laboratory \\ experiments: i) non-breaking waves over a horizontal sand bed (Schretlen et al., 2011) and ii) plunging breaking \\ waves over a barred mobile bed profile (Van der Zanden et al., 2016). For the first time, the model is not only \\ tested and validated in terms of water surface and outer flow hydrodynamics, but also in terms of wave boundary \\ layer processes and sediment concentration patterns. It is shown that the model is capable of reproducing the \\ outer flow (mean currents and turbulence patterns) as well as the spatial and temporal development of the wave \\ boundary layer. The simulations of sediment concentration distributions across the breaking zone show the \\ relevance of accounting for turbulence effects on computing suspended sediment pick-up from the bed.
}

Keywords: wave boundary layer; turbulence model; plunging breaking waves; sediment transport

\section{INTRODUCTION}

An accurate prediction of sediment transport is essential to properly simulate near-shore morphodynamics. At present, although sediment transport formulas account for the main processes that drive sediment transport under non-breaking waves, they lack prediction skill of transport rates and bottom changes in the breaking zone. In fact, there is a general lack of understanding the effects of wave breaking hydrodynamics and turbulence on sediment transport. The latter holds particularly for the wave bottom boundary layer processes and near-bed transport $(O(\mathrm{~mm}-\mathrm{cm})$ above the bed); a region which has not been considered in-depth during most previous experimental and numerical surf zone studies.

Most previous field and laboratory surf zone studies focused on outer flow velocity and turbulence (e.g. Ting and Kirby, 1994; Scott et al., 2005; Yoon and Cox, 2010; Ruessink et al., 2011; Grasso et al., 2012) or on outer flow suspended sand concentration and flux (Yoon and Cox, 2012; Aagaard and Jensen, 2013; Brinkkemper et al., 2017). These studies have helped to understand wave-breaking dynamics and their effects on sand suspension, but wave boundary layer processes and near-bed sediment fluxes were disregarded. Recently, the outer-flow and wave boundary layer hydrodynamics and sediment dynamics were measured with high spatial and temporal resolution during large-scale plunging waves experiments of Van der Zanden et al. $(2016,2017)$ (mobile bed barred profile) and Van der A et al. (2017) (fixed bed barred profile). Both flume experiments aimed to get more insights on the effects of wave breaking on hydrodynamics and sediment transport, with special emphasis on measuring wave boundary layer processes along the wave breaking zone.

The wave boundary layer flow and sand transport in oscillatory flows and under non-breaking waves has been successfully simulated with 1DV RANS models (e.g. Holmedal and Myrhaug, 2006; Hassan and Ribberink, 2010; Kranenburg et al., 2013). These models are forced under local conditions, and horizontally non-uniform advective processes are not fully accounted for. Consequently, these models are not applicable to the wave breaking region, where bi-dimensional ( $x-z$ direction) advective processes are relevant. 2D and 3D Boussinesq, RANS, LES and DNS models have been used to study water surface, flow and turbulence dynamics (among others Christensen et al., 2002; Zhao et al., 2004; Christensen, 2006; Torres-Freyermuth et al., 2007; Xie, 2012; Jacobsen et al., 2012; Brown et al., 2016; Zhou et al., 2017) under breaking waves. However, they have been generally tested for small-scale breaking wave experiments, disregarding wave boundary layer processes and sediment transport.

The present study aims to overcome this gap by assessing the capability of a morphodynamic RANS-VOF model (Jacobsen et al., 2014; Jacobsen and Fredsøe, 2014) on simulating processes under non-breaking waves and under breaking waves conditions to be further used as a tool to investigate wave breaking effects on hydrodynamics and sediment transport over the whole water column. First, the model is applied to reproduce wave boundary layer hydrodynamics and sediment transport under full-scale non-breaking waves (Schretlen et al., 2011). Subsequently, the full-scale wave breaking experiments by Van der Zanden et al. $(2016,2017)$ is simulated, allowing validation of the model in terms of the global outer-flow processes (breaking process, outer flow velocity, turbulence) as well as the wave-boundary layer processes and sediment transport dynamics.

\footnotetext{
${ }^{1}$ Water Engineering and Management Group, University of Twente, The Netherlands

${ }^{2}$ Water Engineering and Management Group, University of Twente, The Netherlands

${ }^{3}$ Water Engineering and Management Group, University of Twente, The Netherlands

${ }^{4}$ Marine \& Coastal Systems, Deltares, Delft, The Netherlands

${ }^{5}$ Coastal Structures and Waves, Deltares, Delft, The Netherlands
} 
In the following, the numerical model is first briefly explained. Next, the experimental conditions, numerical setup and results for the non-breaking waves simulations are detailed. Subsequently, the experimental conditions, numerical setup and results for the plunging waves simulations are presented. Finally, the results are discussed together with the main conclusions.

\section{NUMERICAL MODEL}

The Jacobsen et al. (2014) model is a two-phase (water-air) RANS morphodynamic model, based on the open-source computational toolbox OpenFoam $\AA$, that couples hydrodynamics, sediment transport and bottom changes. This model has been tested previously in terms of outer flow and turbulence for laboratory experiments of spilling and plunging breaking waves over plane-sloping and barred beaches (Jacobsen et al., 2012, 2014; Brown et al., 2016), and has been successfully used for full-scale morphodynamic evolution simulations (Jacobsen et al., 2014; Jacobsen and Fredsøe, 2014). The model solves the two-phase Reynolds Averaged Navier-Stokes equations, i.e. mass conservation and momentum balance conservation. In the present work, the $k-\omega$ SST model (Menter, 1994) is used for the turbulence closure problem. This turbulence model adopts the advantages of two more classical turbulence models (the Rodi (1993) $k-\epsilon$ model and the Wilcox (1988) $k-\omega$ model) to solve the free-stream and the boundary layer turbulence field, respectively. The corrected $k-\omega$ SST model reads

$$
\begin{gathered}
\frac{\partial \rho k}{\partial t}+\frac{\partial}{\partial x_{i}}\left(\rho k u_{i}\right)=\frac{\partial}{\partial x_{j}}\left[\rho\left(v+\frac{v_{T}}{\sigma_{k}}\right) \frac{\partial k}{\partial x_{j}}\right]+\min \left(P_{k}, \rho c_{1} C_{\mu} k \omega\right)-\rho C_{\mu} \omega k \\
\frac{\partial \rho \omega}{\partial t}+\frac{\partial}{\partial x_{i}} \rho \omega u_{i}=\frac{\partial}{\partial x_{j}}\left[\rho\left(v+\frac{v_{T}}{\sigma_{\omega}}\right) \frac{\partial \omega}{\partial x_{j}}\right]+\gamma \frac{\omega}{k} P_{k}-\beta \omega^{2}+2\left(1-F_{1}\right) \frac{\sigma_{\omega 2}}{\omega} \frac{\partial k}{\partial x_{i}} \frac{\partial \omega}{\partial x_{i}}
\end{gathered}
$$

where $v_{T}=a_{1} k / \max \left(a_{1} \omega, f(k, \omega)\right)$ is the turbulent kinetic viscosity, $F_{1}$ is a blending function that switches the model to a $k-\epsilon$ model in the free stream and to a $k-\omega$ model in the inner zone of the boundary layer (further detailed in Menter, 1994), and $\sigma_{k},\left[\sigma_{\omega}, \sigma_{\omega, 2}\right], \gamma, c_{1}, \beta$ and $C_{\mu}$ are scalar parameters set to $0.85,[0.5,0.85], 0.55,10,0.075$ and 0.09 , respectively. The production term is $P_{k}=\rho v_{t}|S|^{2}$, where $S=\sqrt{2 S_{i j} S_{i j}}$ and $S_{i j}=1 / 2\left(\partial u_{i} / \partial x_{j}+\partial u_{j} / \partial x_{i}\right)$ is the mean strain rate of the flow.

In order to account for bed roughness effects on hydrodynamics and sediment transport, and following Jacobsen et al. (2012), the bottom is considered hydraulically rough and the theoretical bed level is set at the top of the roughness element $z_{0}=k_{N} / 30$. By imposing a no-slip condition for the velocity at the bottom and considering a near-bottom logarithmic profile and equilibrium between turbulence production and dissipation, the boundary conditions at the sand bed are:

$$
\left.u_{i}\right|_{0}=\left.0 \quad k\right|_{0}=\left.\frac{u_{*}^{2}}{\sqrt{C_{\mu}}} \quad \omega\right|_{0}=\frac{u_{*}}{\sqrt{\beta^{*}} \kappa \Delta y}
$$

where $u_{*}$ is the friction velocity, defined through the logarithmic expression $u_{\tau} / u_{*}=1 / \kappa \ln \left(\Delta y / z_{0}\right)$, where $u_{\tau}$ is the tangential velocity with respect to the bottom; $\kappa=0.41$ is the Von Karman constant; $z_{0}$ is the bed roughness which relates to the Nikuradse roughness as $z_{0}=k_{N} / 30$, where $k_{N}=2.5 d_{50}$ and $d_{50}$ is the median bed grain diameter; and $\Delta y$ is the distance from the bottom to the center of the first computational cell.

Sediment transport is computed by considering both suspended and bed-load contributions. Suspended sediment transport is calculated by solving the advection-diffusion equation:

$$
\frac{\partial c}{\partial t}+\frac{\partial}{\partial x_{i}}\left[\left(\gamma u_{i}+w_{s}(x)\right) c\right]-\frac{\partial}{\partial x_{j}}\left[\gamma\left(v+\hat{v}_{T}\right) \frac{\partial}{\partial x_{j}} c\right]=0
$$

where $c$ is the volumetric sediment concentration, $\vec{w}_{s}$ is the sediment fall velocity, $\gamma$ is the volume of fluid (VOF approach) and $\hat{v}_{T}$ is the sediment diffusivity given by $v_{T} / \sigma_{c}\left(\sigma_{c}=1\right)$. Following Zyserman and Fredsøe (1994), a reference concentration $c_{0}$ is computed at a vertical level $z_{a}=2.5 d_{50}$ above the bed as:

$$
c_{0}=\frac{A\left(\theta^{\prime}-\theta_{c}^{\prime}\right)^{n}}{1+\frac{A}{c_{m}}\left(\theta^{\prime}-\theta_{c}^{\prime}\right)^{n}}
$$

where $A$ is set to $0.331, c_{m}$ to 0.46 and $n$ to 1.75 .

The bed-load transport is computed through the extended Engelund and Fredsøe (1976) formula given by Roulund et al. (2005) for 3D and arbitrary slopes as

$$
q_{b}=\frac{1}{6} \pi d_{50} \mathcal{P}_{E F} u_{b} \quad \mathcal{P}_{E F}=\left[1+\left(\frac{\frac{1}{6} \pi \mu_{d}}{\theta^{\prime}-\theta_{c}^{\prime}}\right)^{4}\right]^{-\frac{1}{4}}
$$


in which $u_{b}$ is the mean transport direction; $\mathcal{P}_{E F}$ is the probability of particle motion in the bed; $\theta^{\prime}$ is the instantaneous Shields parameter; $\theta_{c}^{\prime}$ is the critical Shields parameter that includes the bed-slope effects on bed-load transport (Roulund et al., 2005); and $\mu_{d}$ is the dynamic friction function set to 0.60.

Further details on sediment transport and bed level changes computed by the model are given by Jacobsen et al. (2012, 2014) and Jacobsen and Fredsøe (2014). Note that in the present work, bed level changes are not considered.

\section{FULL-SCALE PROGRESSIVE NON-BREAKING WAVES EXPERIMENTS}

To asses the capability of the model to reproduce wave-boundary layer processes, the model is first tested for full-scale progressive non-breaking waves over a horizontal sand bed. The model is validated in terms of intra-wave boundary layer processes and net sediment transport rates.

\section{Experimental conditions and numerical set-up}

The model is used to reproduce the full-scale experiments of Schretlen et al. (2011) and Schretlen (2012), that were conducted in the large wave flume of the Coastal Research Center of Hannover, Germany in 2007 and 2008. The flume is $280 \mathrm{~m}$ long, $5 \mathrm{~m}$ wide and $7 \mathrm{~m}$ deep. During the experiments, a $1.0 \mathrm{~m}$ high mobile bed horizontal test section was created (Figure 1A) for two median grain sizes $d_{50}$ : $0.138 \mathrm{~mm}$ and $0.247 \mathrm{~mm}$ (well-sorted fine and medium sand). The sand bed was exposed to regular trochoidal waves for various wave conditions, generated by the wave paddle at $4.5 \mathrm{~m}$ water depth. Each condition was run for several hours, during runs of 0.5-1 hour duration.

Measurements were obtained over the test section at $x \approx 110 \mathrm{~m}$ from the wave paddle at a local water depth of $3.5 \mathrm{~m}$. Wave boundary layer velocities were measured with high spatial and temporal resolution using an Ultrasonic Velocity Profiler (UVP). Sediment concentrations were measured using a five-nozzle transverse suction system (at elevations $>30 \mathrm{~mm}$ ) and a UHCM (at elevations $<50 \mathrm{~mm}$ ). Before and after each experiment, the bed profile was measured with a mechanic wheel profiler and echo-sounders. Sediment transport rates were determined from the integration of the bottom changes. Figure 1A shows the experimental setup and depicts the location of the instrumental frame. Further details of experiments can be found in Schretlen et al. (2011).
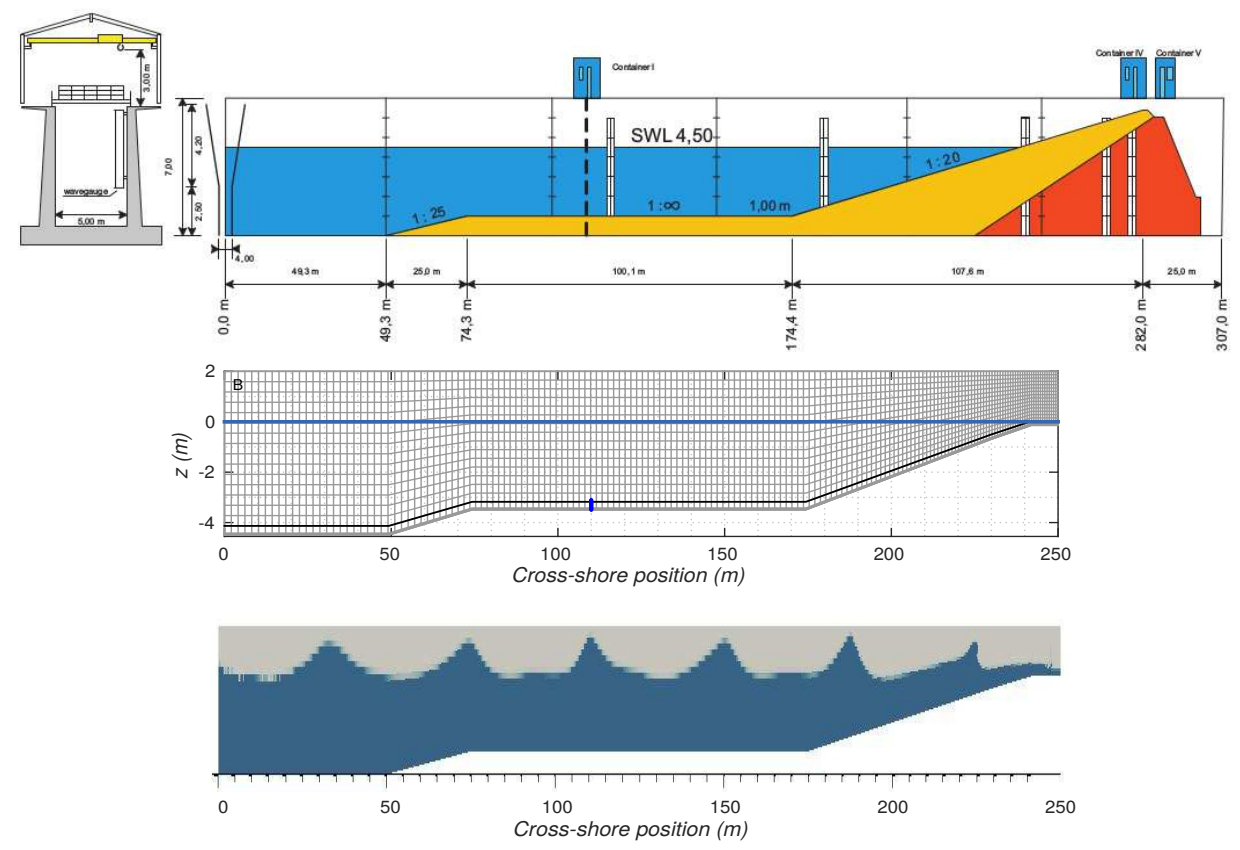

Figure 1: A. Scheme of the bed set-up during the non-breaking wave experiments (source: Schretlen et al. (2011)); B. Computational mesh. For every 20 mesh lines, only one is shown (in both directions); C. Snapshot of simulated water surface evolution (1265f experiment).

The numerical experiments consist of the simulation of the wave propagation over the full $280 \mathrm{~m}$ long wave flume (see Figure 1C). The model domain used to reproduce these experiments is shown in Figure 1B. The model is a vertical slice of the flume in the $x-z$ plane, dismissing processes in the 'alongshore' $x-y$ plane. The bottom bathymetry is the initial horizontal profile of the experiments. 
The computational grid is composed of $1146 \times 76$ points ( $x$ and $z$ direction), with a $\sigma-$ grid following the bathymetry. To obtain an accurate description of the near-bed processes, a high resolution grid close to the bottom is needed. Along the first $5 \mathrm{~cm}$ above the bed the grid height is set to $\Delta y=1$ $\mathrm{mm}$, which is a factor 20-50 smaller than the measured wave boundary layer thickness $\delta_{w}$. The grid is non-uniform with $\Delta x$ ranging from $\approx 0.10$ (near shoreline) to $\approx 0.30$ (near wave paddle) $\mathrm{m}$ and $\Delta z$ from 0.001 to $\approx 0.30 \mathrm{~m}$ (from bed upwards). The grid ratio $\Delta z / \Delta x$ is smallest near the bed. The bed profile is truncated shoreward from the shoreline to ensure a $\Delta z / \Delta x$ ratio equal to 1 in the water-air interphase to ensure the model stability.

At the paddle position $x=0 \mathrm{~m}$, the model is forced under a stream function consistent with the regular trochoidal waves during the experiments. In the present work, four cases are selected, that correspond to variations of wave height, period and grain size during the experiments. Characteristics of these cases are summarized in Table 1. The total simulation time for each simulation is set to 250 $\mathrm{s}$, corresponding to $\approx 40$ waves generated by the paddle, to ensure the warm-up of the model and the establishment of a hydrodynamic equilibrium at the measuring frame position $(x \approx 110 \mathrm{~m})$.

Table 1: Summary of main experimental characteristics.

\begin{tabular}{lcccc}
\hline Experiment & $\begin{array}{c}\mathrm{H} \\
(\mathrm{m})\end{array}$ & $\begin{array}{c}\mathrm{T} \\
(\mathrm{s})\end{array}$ & $\begin{array}{c}d_{50} \\
(\mathrm{~mm})\end{array}$ & $\begin{array}{c}\# \\
\text { runs }\end{array}$ \\
\hline $1265 \mathrm{f}$ & 1.2 & 6.5 & 0.138 & 6 \\
$1565 \mathrm{f}$ & 1.5 & 6.5 & 0.138 & 10 \\
$1565 \mathrm{~m}$ & 1.5 & 6.5 & 0.247 & 14 \\
$1575 \mathrm{~m}$ & 1.5 & 7.5 & 0.247 & 11 \\
\hline
\end{tabular}

Hereafter two kind of variables are presented: the time-dependent ensemble-averaged variables and the wave- or time-averaged variables. Ensemble-averaged values of an arbitrary variable $\chi^{\prime}$ are defined as:

$$
\chi(t)=\frac{1}{N} \sum_{n=1}^{N} \chi^{\prime}(t+(n-1) T)
$$

where $N$ is the number of wave cycles from the equilibrium to the end of the simulation. In this case, the last 6 simulated waves are considered $(N=6)$. Wave-averaged variables are defined as:

$$
\langle\chi\rangle=\frac{1}{N T} \int_{t s}^{N T} \chi(t) d t
$$

where $t s$ is the starting time of the quasi-steady condition.

To assess the model accuracy, the skill parameter $P S$ is computed as

$$
P S=1-\frac{\sum_{0}^{n}\left(\chi_{s i m}^{i}-\chi_{o b s}^{i}\right)^{2}}{\sum_{0}^{n}\left(\chi_{o b s}^{i}-\overline{\chi_{o b s}}\right)^{2}}
$$

where subscripts $o b s$ and sim stand for measurements and simulation results, respectively, and $\overline{\chi_{o b s}}$ is the mean of the $n$ observations.

\section{Wave boundary layer processes}

Figure 2A shows the measured and simulated ensemble-averaged horizontal velocity $u_{x}(t)$ during the wave cycle at different elevations above the bed (in and outside the boundary layer) for the four cases. The model captures the magnitudes of intra-wave velocities properly: the maximum (onshore directed) and minimum (offshore directed) velocities at the different levels are well simulated. To further quantify the model skill, the mean skill parameter $P S$ for all the cases along the wave boundary layer (Equation 9) for the maximum and minimum velocity and both velocity skewness and asymmetry (as shape indexes) are computed. Model results show an overall high model skill in terms of velocity amplitude $\left(P S_{u_{\max }}=0.99\right.$ and $P S_{u_{\min }}=0.98$, for the maximum (onshore) horizontal velocity and the minimum (offshore) horizontal velocity, respectively), as well as in terms of the near-bottom velocity skewness $P S_{\text {skew }}=0.98$. Lower model skill values are given by the asymmetry parameter $\left(P S_{A s}=0.83\right)$. We should bear in mind that the resulting velocity field from the present $2 \mathrm{D}$ RANSVOF simulations is the result of the propagation of progressive waves along the $280 \mathrm{~m}$ long profile, unlike previous numerical studies on modelling wave boundary layer processes (Holmedal and Myrhaug, 
2006; Hassan and Ribberink, 2010; Kranenburg et al., 2013), that are locally forced with measured velocities and solve only few centimeters above the bed.
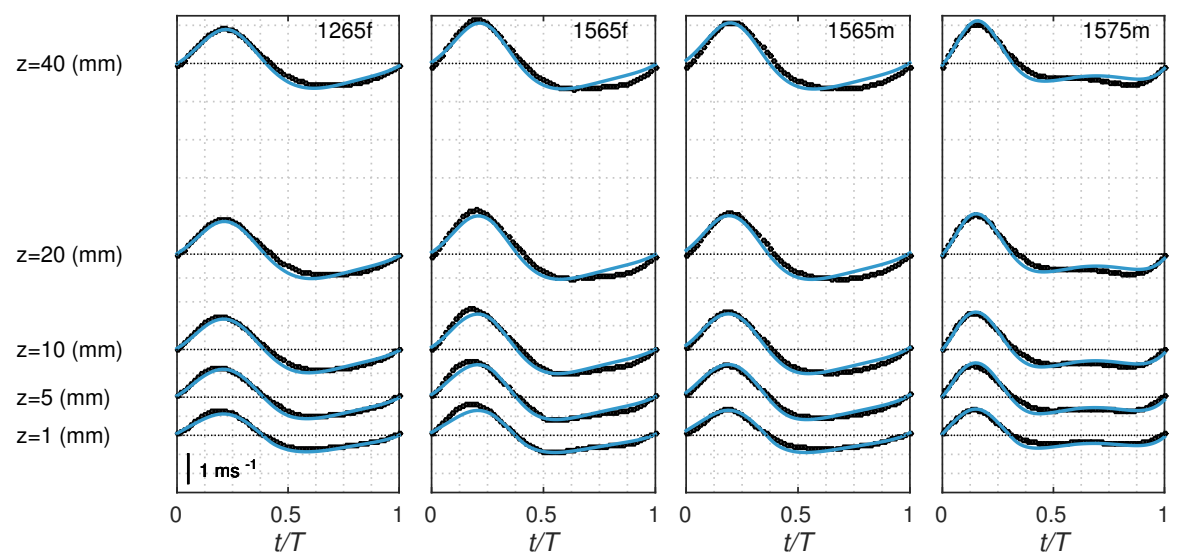

Figure 2: Time-series of measured (black dots, UVP) and simulated (blue solid lines) horizontal velocity $u_{x}(t)$ at different elevations above the horizontal bed for the four experiments (from left to right: 1265f, 1565f, $1565 \mathrm{~m}$ and $1575 \mathrm{~m})$.

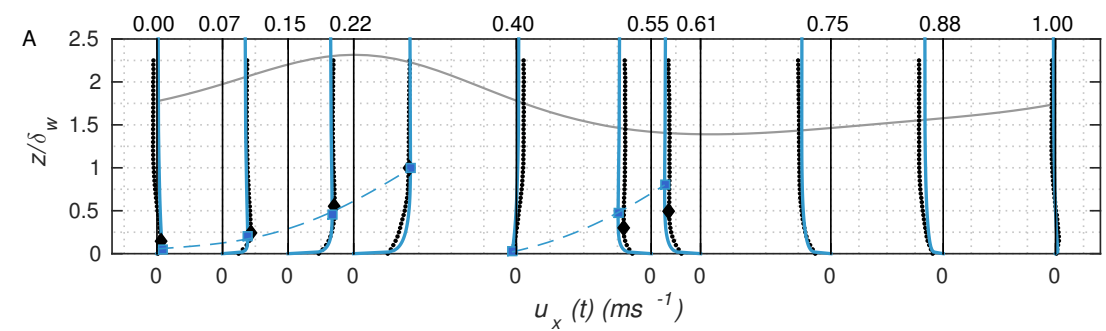

$t / T$

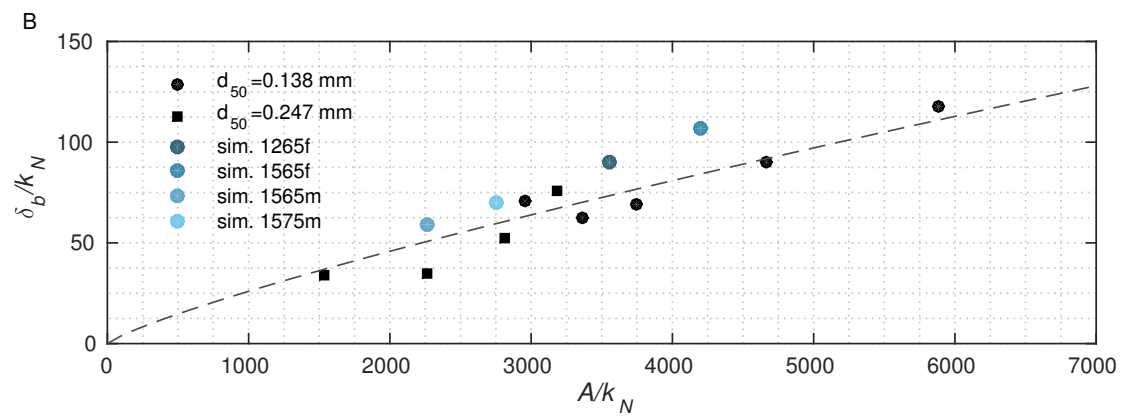

Figure 3: A. Vertical profiles of measured (black dots) and simulated (blue solid line) horizontal velocity at different phases of the wave cycle, case 1265f. The free-stream velocity $u_{\delta}$ (gray solid line) is shown for reference. Also included are the upper limits of the instantaneous wave boundary layer, obtained from the measurements (black diamond symbols) and simulations (blue squares and bluedashed lines). B. Dimensionless wave boundary layer thickness $\delta_{b} / k_{N}$ as function of the dimensionless orbital excursion length $A / k_{N}$, from measurements (black symbols) and simulations (blue symbols). The dashed line depicts the empirical relation by Fredsøe and Deigaard (1992).

Figure 3A shows the measured and simulated vertical profiles of the horizontal velocity $u_{x}(t)$ for different wave phases of the $1265 \mathrm{f}$ case. The wave boundary layer development can be tracked by the upward migration of the velocity overshoot elevation during the wave cycle (Jensen et al., 1989; Fredsøe and Deigaard, 1992). We first point out that the model is able to reproduce the intra-wave growth of the wave boundary layer during both the wave crest and the wave trough half-cycle. The boundary layer reaches a higher thickness during the crest phase than during the trough phase, which is consistent with the measurements, and which is explained by higher crest-phase velocity magnitudes under the positively skewed waves.

Figure 3B shows the dimensionless $\delta_{w} / k_{N}$ versus $A / k_{N}$ for both measurements and simulations. 
Also included are predictions using the empirical model of Fredsøe and Deigaard (1992), which is computed as $\delta_{w} / k_{N}=0.09\left(\hat{A}_{\delta} / k_{N}\right)^{0.82}$, in which $\hat{A}_{\delta}$ is the free-stream semi-excursion length. The trends of simulated wave boundary layer thickness are consistent with both measurements and empirical estimations. However, the numerical model systematically overpredicts $\delta_{w} / k_{N}$ (in $\approx 25 \%$ ).

\section{Sediment transport rates}

The total sediment transport $\left\langle Q_{t}\right\rangle$ is computed as the summation of the simulated bed-load transport given by Engelund and Fredsøe (1976) and the total suspended transport $\left\langle Q_{s}\right\rangle={ }^{1} / T \int_{0}^{T} \int_{z_{a}}^{\eta} c(z, t) u_{x}(z, t) d z d t$.

Figure 4 shows the total sediment transport rates (measurements and simulations) as a function of the dimensional near-bottom orbital velocity skewness $\left\langle u_{\delta}^{3}\right\rangle$. The black dashed line stands for the trend line given by the Schretlen et al. (2011) measurements. Simulated transport rates are in the proper direction (onshore) and are within a factor 2 from the measurements. Such deviations can be considered acceptable (Davies et al., 2002) given the uncertainties during the experiments. The net total transport is almost fully due to suspended transport. The net bed-load transport rates $\left\langle Q_{b}\right\rangle$ are one order of magnitude lower than the net suspended transport rates (here not shown).

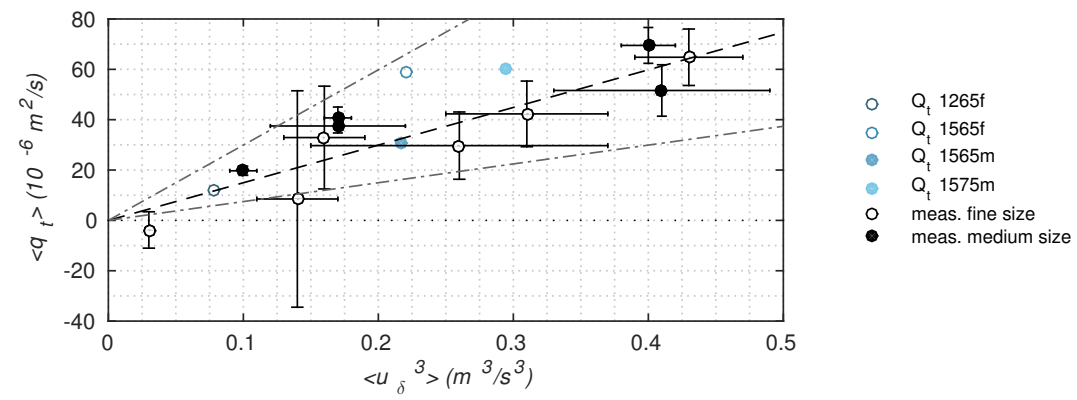

Figure 4: Net total sediment transport rates versus the near-bottom orbital velocity moment $\left\langle u_{\delta}^{3}\right\rangle$. The measurements are depicted by the white circles (fine sand) and black circles (medium sand) and the error bars. Blue circles depict the results from numerical simulations. Dashed line marks the mean trend line; dot-dashed lines depict a factor $2(0.5)$ from this mean trend.

\section{FULL-SCALE BREAKING WAVES EXPERIMENTS}

In the previous section, we assessed the model's performance to simulate wave boundary layer processes and sediment transport rates under non-breaking waves above a horizontal bed. In the present section, we test the model's performance for a more complex scenario of full-scale plunging breaking waves over a sand bar.

\section{Experimental conditions and numerical set-up}

The numerical model is used to reproduce recent large-scale wave flume experiments involving breaking waves over a mobile bed (details given by Van der Zanden et al., 2016, 2017). The bed profile was composed of well-sorted medium-grained sand $\left(d_{50}=0.24 \mathrm{~mm}\right.$, fall velocity $\left.w_{s}=0.034 \mathrm{~m} / \mathrm{s}\right)$. The initial bed consisted of a 1:10 offshore slope, a distinct bar-trough geometry, a mildly sloping (1:80) inner surf zone, and a 1:7.5 beach (Figure 5A). The beach was fixed with geotextile and covered with perforated concrete slabs to promote wave energy dissipation.

The primary instrumentation was deployed from a horizontally and vertically mobile measuring frame. Near-bed sand concentrations and particle velocities were measured with a 2-component $(u, w)$ Acoustic Concentration and Velocity Profiler, ACVP (Hurther et al., 2011). The ACVP sampled over a vertical profile of 10 to $15 \mathrm{~cm}$ with $1.5 \mathrm{~mm}$ vertical bin resolution and $70 \mathrm{~Hz}$ sampling frequency, hence capturing the complete wave bottom boundary layer with high resolution. Outer-flow velocities were measured with three ADVs at $0.11,0.41$ and $0.80 \mathrm{~m}$ above the initial bed level. The ADV and ACVP velocity measurements were decomposed into a mean, orbital and turbulent signal following a Reynolds decomposition based on ensemble-averaging. The phase-averaged turbulent kinetic energy was then calculated based on the turbulence intensities.

Time-averaged suspended sand concentrations were measured at six elevations using a transverse suction system (TSS). Instantaneous near-bed concentrations were measured by the ACVP through inversion of the acoustic backscatter voltage, using the TSS measurements for calibration. Water surface levels were measured across the test section with pressure transducers (PTs) and resistive wave gauges 
(RWGs).

The wave paddle generated regular waves with wave period $T=4 \mathrm{~s}$ and wave height $H=0.85$ $\mathrm{m}$ near the wave paddle at $h_{0}=2.55 \mathrm{~m}$, resulting in plunging breaking waves at the bar crest. One experiment consisted of six 15-minute runs. After the 90-min. experiment, the flume was drained and the initial bed profile was restored. The experiment was repeated 12 times, with instruments located at a different cross-shore position for each repeat, yielding a high spatial coverage of measurements (Figure 5B).
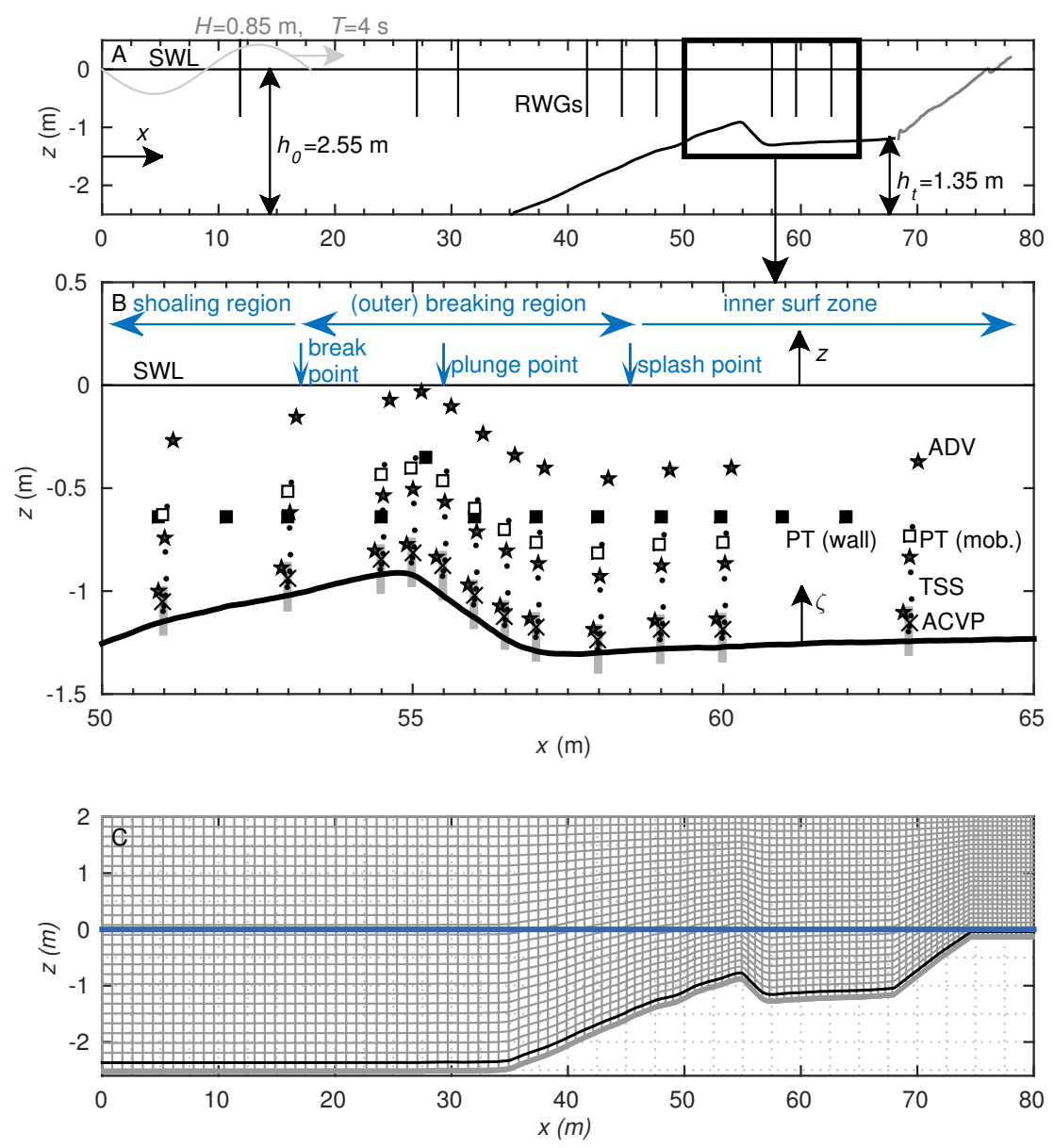

Figure 5: Experimental and model set-up for breaking wave case. A. General overview of wave flume, including initial bed profile (solid bold black line), fixed beach (solid grey line), and locations of resistive wave gauges (black vertical lines); B. Close-up of test section, including instrument positions: mobileframe pressure transducer (PT mob.; white squares); side-wall-deployed PTs (black squares); mobileframe ADVs (stars); and ACVP profiles (grey rectangles) (adopted from Van der Zanden et al., 2016). C. Computational domain and grid. Every 20th ( $x$ direction) and 5th ( $z$ direction) grid line is plotted. The black line indicates the upper level of the $1 \mathrm{~mm}$ cells near the bed.

Figure 5C shows the model domain used to reproduce these experiments. Similar to the nonbreaking waves case, the domain is a vertical slice of the flume in the $x-z$ plane. The bottom bathymetry is the initial barred profile of the experiment. The computational grid is composed of $1543 \times 81$ points ( $x$ and $z$ direction), conforming $\approx 125000$ cells, with a $\sigma$-grid following the bathymetry. Similar to the previous case, a high vertical resolution close to the bottom is used, with a cell height of $1 \mathrm{~mm}$ for the lowest $0.05 \mathrm{~m}$. The grid is non-uniform with $\Delta x$ ranging from $\approx 0.02 \mathrm{~m}$ (wave breaking region) to $\approx 0.06 \mathrm{~m}$ (near wave paddle) and $\Delta z$ from 0.001 to $\approx 0.06 \mathrm{~m}$ (from bed upwards). The grid ratio $\Delta z / \Delta x$ is smallest near the bed. The bed profile is truncated shoreward from the shoreline to ensure a $\Delta z / \Delta x$ ratio equal to 1 in the water-air interface.

The model is forced at the wave paddle with regular first order Stokes waves $(H=0.85 \mathrm{~m}, T=4 \mathrm{~s})$, consistent with the experiments. The total simulation time is set to $600 \mathrm{~s}$, corresponding to 150 waves 
generated by the paddle, to ensure the warm-up of the model and the establishment of a hydrodynamic equilibrium.

Three regions are defined based on the observations and following definitions of Svendsen et al. (1978): the shoaling region, offshore from the break point in which wave surface starts curling; the breaking area, between the break point and the the splash point where a surf bore is formed, that includes the plunge point where the plunging jet strikes the water surface, and the inner-surf zone, shoreward from the splash point (Figure 5B).

\section{Surface dynamics}

Figure 6 shows the water surface elevation along the profile at different phases during the wave cycle together with the PT and RWG measurements. The reference time $t=0 \mathrm{~s}$ is set at the zeroup-crossing of the water surface elevation $\eta(t)$ at $x=50.9 \mathrm{~m}$. The model results agree well with the measurements for all phases. Note that the water surface elevation is overestimated during the breaking process by a maximum of $\approx 0.2 \mathrm{~m}$ (see second and third panels in the figure), but this could also be due to the applied dynamic pressure conversion of the measured PT signal to water surface level, which underestimates $\eta(t)$ when waves are very steep.

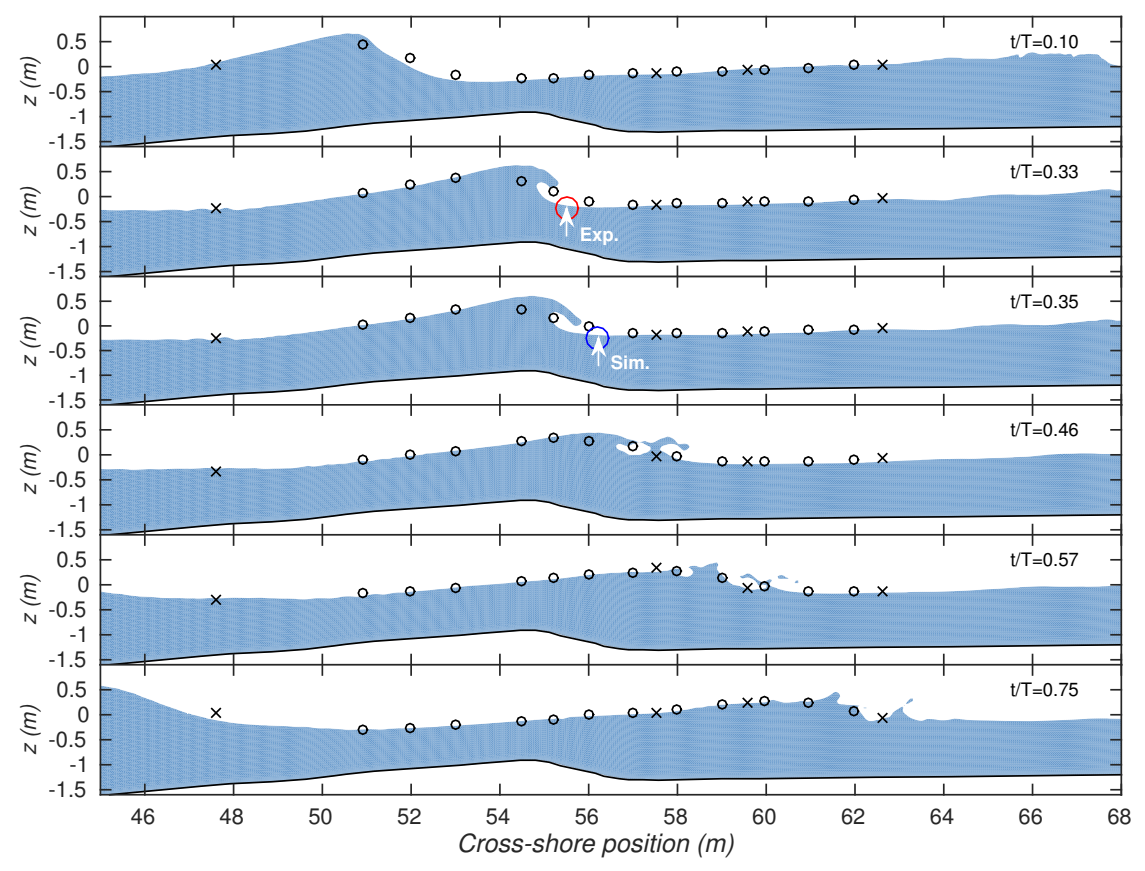

Figure 6: Water surface levels at different phases during the wave cycle. Black circles and crosses indicate measurements by PTs and RWGs, respectively. The red and blue circles indicate the positions of the plunge point during the experiment and in the simulations, respectively.
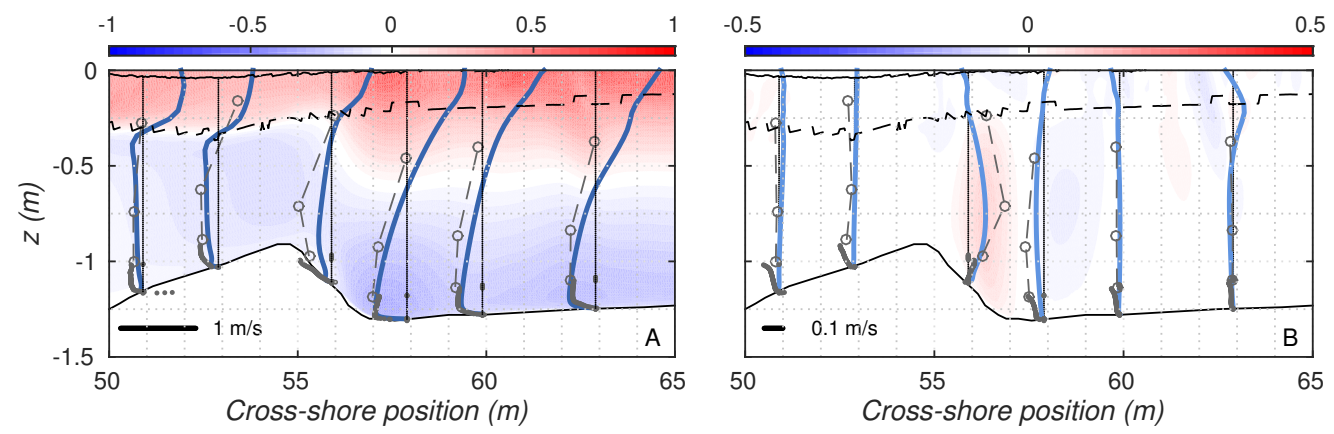

Figure 7: Vertical profiles of A. mean horizontal velocity (undertow) $\left\langle u_{x}\right\rangle$, B. mean vertical velocity $\left\langle u_{z}(t)\right\rangle$. Circles stand for the ADV measurements, dots for the ACVP measurements and blue lines for simulation results. Contours show the simulated $\left\langle u_{x}\right\rangle$ and $\left\langle u_{z}\right\rangle$, respectively.

The plunge point is found in the model at $x=56.2 \mathrm{~m}$ (blue circle in Figure 6), $0.7 \mathrm{~m}$ shoreward 
from the plunge point observed during the experiment (red circle in Figure 6) at $x=55.5 \mathrm{~m}$. This onshore shift of the plunge position leads to a similar horizontal shift of other hydrodynamic parameters, as will be discussed in the following sections.

\section{Outer flow}

Figure 7 shows the time-averaged horizontal and vertical velocities $\left(\left\langle u_{x}(t)\right\rangle\right.$ and $\left.\left\langle u_{z}(t)\right\rangle\right)$. In the shoaling and inner-surf zones, the modelled horizontal velocity profile (undertow) shows good agreement with the ADV and ACVP measurements. However, the strong offshore directed current above the lee side of the sandbar is underestimated. This is attributed to the shoreward shift of the plunge point in the simulations with respect to the measurements, as commented above. In the model, waves break closer to the bar trough. Consequently, the return fluxes, that balance the wave breaking related onshore-directed mass fluxes near the water surface, are distributed over a larger water depth than in the experiments. This also leads to an underestimation of $\left\langle u_{z}(t)\right\rangle$ over the lee side of the sandbar (Figure $7 \mathrm{~B})$. Note that both in the measurements and simulations, the upwards directed mass flux at $x \approx 55.5$ $\mathrm{m}$ and the downward flux at $x \approx 58 \mathrm{~m}$ are indicative of a two-dimensional undertow circulation. This circulation was also observed during the fixed bed experiment (Van der A et al., 2017) and other surf zone studies (e.g. Dyhr-Nielsen and Sørensen, 1970; Jacobsen and Fredsøe, 2014).

\section{Wave boundary layer dynamics}

Figure 8 shows the measured (by ACVP) and simulated vertical profiles of the near-bed velocity for different phases of the wave cycle. The measured and simulated velocities were transformed to a bed-parallel and bed-normal component; the figure shows the bed-parallel velocity. Similar to the non-breaking wave case, we first point out that the model is able to reproduce the intra-wave growth and break-up of the wave boundary layer (panels B in Figure 8), which follows from observing the position of the velocity overshoot for different phases. To the authors' knowledge, this is the first time the boundary layer development under breaking waves is reproduced using a RANS-VOF model. Although the overshoot in the simulations is not as distinct as in the measurements, other boundary layer characteristics are properly captured, such as the velocity amplitudes, the spatial and temporal trends, and the durations of the onshore and offshore half cycles (especially well-represented in the inner-surf zone, $x>58.5 \mathrm{~m}$ ). During the experiments, velocity amplitudes within the wave boundary layer decrease rapidly after the plunge point (Figure 8A, 2nd to 3rd panel). This decrease in amplitude occurs further shoreward in the simulations, because the plunge point is also shifted. This explains the overestimation of velocity amplitudes at $x=55.9$ and $56.9 \mathrm{~m}$ by the model.
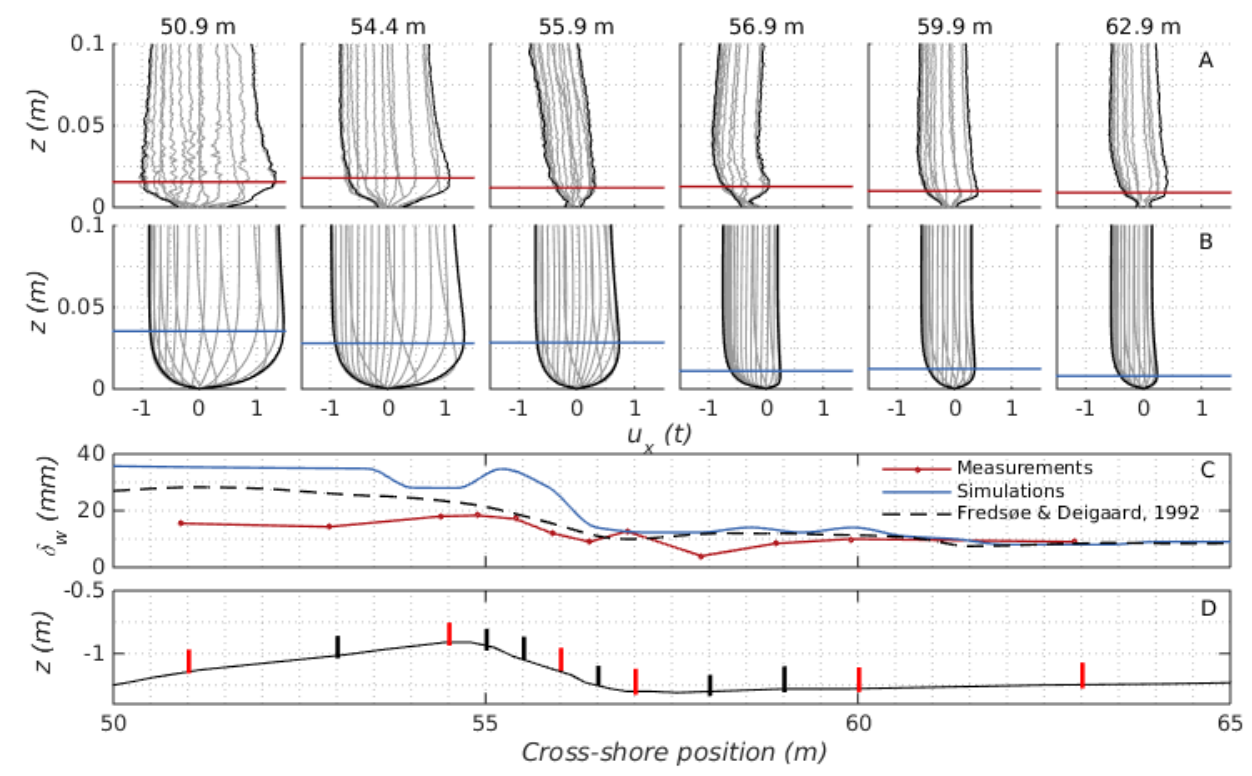

Figure 8: Vertical profiles of the measured (panels A) and simulated (panels B) bed-parallel velocity $u_{x}(t)$ for 0 to $0.10 \mathrm{~m}$ above the bed at six locations. Red and blue lines indicate the wave boundary layer thickness for the measurements and simulations, respectively. C. Wave boundary layer thickness along the profile for measurements (red solid line), simulations (blue solid line) and empirical predictions following Fredsøe and Deigaard (1992) based on the simulated free-stream velocity (dashed line). Panel $D$ indicates the positions of the ACVP measurements along the profile for reference (red dots indicate the positions of velocity profiles shown in the upper panels. 
Figure 8C shows the cross-shore distribution of the wave boundary layer thickness $\delta_{w}$ based on measurements, simulations, and the empirical predictor of Fredsøe and Deigaard (1992). The model systematically overestimates $\delta_{w}$ in the shoaling zone (consistent with the overestimation observed under non-breaking waves in previous sections), but agrees with measurements in the inner-surf zone. Note that the model assumes a plane bed roughness along the profile, while during the experiment, the bed was plane in the shoaling and breaking zones (i.e. sheet flow conditions), but sand ripples were present in the inner surf zone. The model follows the trends of the Fredsøe and Deigaard (1992) prediction rather well. Slightly shoreward of the bar crest $(x=55-56 \mathrm{~m})$, the measured and simulated wave boundary layer thickness both reveal a local increase. Van der Zanden et al. (2016) attributed this to the invasion of wave breaking turbulence into the wave bottom boundary layer (c.f. Fredsøe et al., 2003) and/or to flow divergence along the steep slope (c.f. Sumer et al., 1993). These processes are not accounted for in the Fredsøe and Deigaard (1992) approach, and consequently the local increase is not captured by this empirical model.

\section{Turbulence field}

Because of the importance of wave breaking turbulence for sediment transport, the model is also validated in terms of turbulent kinetic energy $k$. Figure 9A shows the simulated $k(t)$ field for different phases of the wave cycle. During the breaking process, significant turbulence is produced at the water surface when the wave curls and the plunging jet enters the water column above the bar trough $(t / T=0.33$ to 0.57$)$. Note that wave breaking turbulence extends vertically all the way down to the bed, especially at the shoreward slope of the bar and at the breaker trough, which is consistent with the measurements. When the breaking wave and surf bore have passed, $k(t)$ decreases as turbulence dissipates (between $t / T=0.75$ to 0.10 ). However, wave breaking turbulence is still persistent in the bar trough region upon the arrival of the next breaking wave (upper panel). This indicates that wave breaking turbulence does not decay fully within one wave cycle, and instead residual turbulence persists into the next wave cycle. This is again consistent with observations. Van der A et al. (2017) related this residual turbulence to the bar-trough geometry, which enables the formation of large-scale breaking-generated turbulent vortices with temporal scales close to the wave period. High in the water column, the wave breaking induced turbulence is partly advected offshore over the sandbar crest by the undertow and orbital velocities (between $t / T=0.35$ and 0.46 ), while another part is advected towards the shoreline by the onshore velocities under the secondary wave formed during wave breaking $(t / T=0.57$ and 0.75$)$.

Figure 9B compares the vertical profiles of the mean normalized turbulence $[\langle k\rangle /(g h)]^{0.5}$ for both measurements (ADVs and ACVPs) and simulations along the profile. The model systematically overpredicts turbulence. This is common behavior of RANS models, regardless of the turbulence closure model used (among others Christensen, 2006; Bakhtyar et al., 2009; Xie, 2013; Jacobsen et al., 2014; Brown et al., 2016; Zhou et al., 2017). Both measurements and simulations show a gradual increase in $\langle k\rangle$ in the upper part of the water column from the shoaling to breaking region, followed by a decrease towards the inner-surf zone.

The same trend appears from the depth-averaged $\langle k\rangle$ (Figure 9C). The figure again shows the model overprediction of $\langle k\rangle$ at almost all locations, especially in the shoaling zone $(x<53 \mathrm{~m})$ and around the plunge point $(x \approx 57 \mathrm{~m}$ in the model). It should be kept in mind that turbulence closure models were originally developed for different conditions than the present oscillatory and highly energetic and turbulent surf zone flow. Despite the difference in magnitude, the cross-shore variation of $\langle k\rangle$ is qualitatively similar to the measurements with a local maximum close to the plunge point. The maximum is shifted shoreward in the simulations, due to the shift of the plunge point.

Figure $9 \mathrm{C}$ also shows the near-bed turbulent kinetic energy depth-averaged over the wave boundary layer. For both measurements and simulations, there is a local maximum near the bottom at the same position of the outer-flow maximum ( $x \approx 56.0 \mathrm{~m}$ for measurements; $x \approx 57.5 \mathrm{~m}$ for the model). This is explained by the invasion of the breaking-induced turbulence into the wave boundary layer (Van der Zanden et al., 2016), which is also captured by the model.

In the shoaling zone, measured $\langle k\rangle$ levels were minor, while the model predicts significant background turbulence near the bed and at outer flow elevations. To further understand the nature and origin of this background turbulence in the simulations and its overestimation compared to the measurements, the measured and modelled turbulent kinetic energy turbulence budget should be explored in depth.

\section{Sediment concentration and suspended transport fluxes}

Figure 10A shows the vertical profiles of the time-averaged sediment concentration $\langle c\rangle$ at different cross-shore locations for both TSS and ACVP measurements and simulations. Generally, the model predicts the spatial trends of sediment concentration profiles. Both in measurements and simulations, 

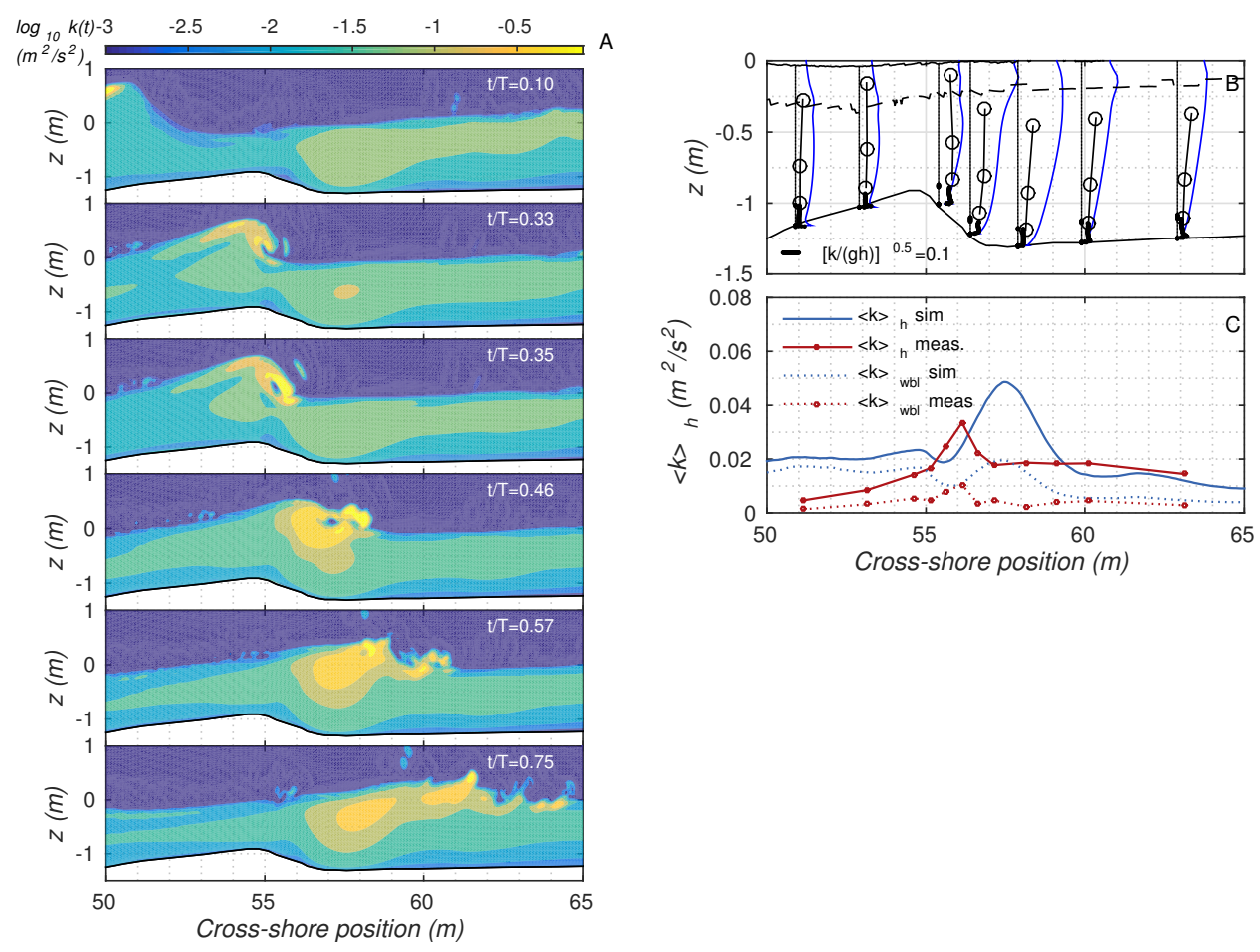

Figure 9: A. Contours of the turbulent kinetic energy $k(t)$ at different phases during the wave cycle. B. Vertical profiles of the normalized turbulence $[\langle k\rangle /(g h)]^{0.5}$. C. Cross-shore distribution of the depthand wave-averaged turbulent kinetic energy $\langle k(t)\rangle$ (red, measurements; blue, simulations). Solid lines, depth-averaged over the water column; dotted lines, depth-averaged over the wave boundary layer.

$\langle c\rangle$ profiles reveal distinct cross-shore variation, with a strong increase of the near-bottom concentrations in the breaking region and a decrease in the inner-surf zone. In the breaking zone, sediment concentrations increase over the full water column, compared to the shoaling and inner surf zones. This is attributed to the strong mixing by the wave-breaking turbulence and to upward advection by the two-dimensional undertow circulation (Van der Zanden et al., 2017). The model also captures this increased mixing in the breaking zone to some extent (by the entrainment of sediment up to the water column), which supports the magnitudes and spatial distribution of the turbulent kinetic viscosity $v_{T}$, that connects to the sediment concentration profile through the sediment diffusivity $\hat{v}_{T}$ (Equation 4).

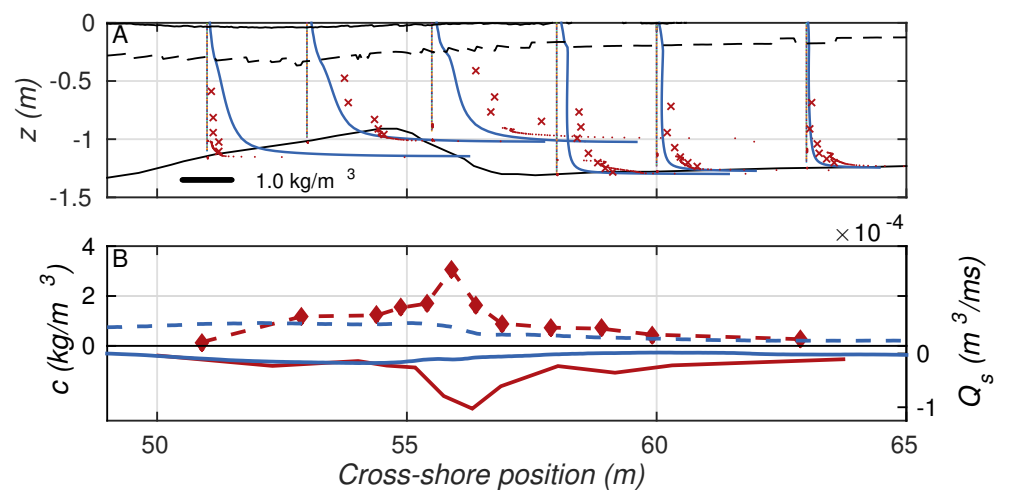

Figure 10: A. Vertical profiles of the time-averaged sediment concentration $\langle c(t)\rangle$ along the profile, measurements (TSS, red crosses; ACVPs, red dots) and simulations (blue solid lines). B. Cross-shore distribution of depth- and time-averaged concentration $\langle c\rangle$ (red-dashed line, measurements; blue-dashed line, simulations) and net depth-integrated suspended transport rates $Q_{s}$ (red solid line, measurements; blue solid line, simulations).

However, on analyzing the magnitude of the depth-averaged concentration across the shoaling and the breaking zone clear discrepancies between measurements and simulations can be observed (Figure 
10B). In particular, the model underestimates the strongly increasing suspended sand load around the plunge point $(x=55.5 \mathrm{~m})$, while it overpredicts the suspended load in the shoaling region. Several studies have stressed that there is a close relation between sediment pick-up and wave-breaking related turbulence (Nadaoka et al., 2011; Hsu and Liu, 2004; Van der Zanden et al., 2017; Zhou et al., 2017). This can be observed on the position of the maximum depth-averaged and near-bed averaged turbulence shown in Figure 9C, that matches the position of the maximum sediment concentration. In the present model, turbulence effects are not accounted for in the reference concentration definition (Equation 5) which may explain the underestimation of $\langle c\rangle$ in the breaking region. Note that the overestimation of $\langle c(t)\rangle$ in the shoaling region may relate to the local overprediction of wave boundary layer thickness $\delta_{w}$, $k(t)$ and $v_{T}$ and, consequently, $\hat{v}_{T}$.

Figure 10B also shows the depth-integrated net suspended transport rates for both measurements and simulations. The differences between measured and modelled $\left\langle Q_{s}\right\rangle$ are significant and relate directly to aforementioned differences in the time- and depth-averaged suspended sand concentrations. The model simulates an offshore directed suspended transport in the shoaling zone that gradually decreases along the breaking region. The local offshore directed maximum in the plunge point observed in the measurements is not reproduced. This emphasizes again the need for accounting for wave breaking turbulence processes in computing the suspended sediment transport, and particularly, in the pick-up function.

\section{CONCLUSIONS}

In the present work, a RANS-VOF model has been validated for two full-scale laboratory experiments: first, for non-breaking waves propagating over a horizontal sand bed (Schretlen et al., 2011); second, plunging breaking waves over a mobile bed barred breaker bar profile (Van der Zanden et al., 2016). The high-resolution near-bed measurements provided by both experiments allowed for the first time to validate this type of model in terms of detailed near-bed hydrodynamics and sediment transport processes.

The modelled water surface evolution, validated for the breaking wave experiment, showed good agreement with the measurements, reinforcing previous works on numerical modeling of small-scale breaking-wave experiments. The modelled breaking location is shifted by about $1 \mathrm{~m}$ shoreward relative to the measurements. The model also simulates the mean outer flow characteristics properly, including the capture of the overall two-dimensional undertow circulation. The simulated magnitudes of the offshore-directed undertow above the sandbar are underestimated, particularly in the middle of the water column, which is attributed to the offset in wave breaking location.

A noteworthy outcome is the model's capability to reproduce the temporal wave boundary layer development. Moreover, the model simulates the proper response of maximum wave boundary layer thickness to changing wave characteristics and grain size (under non-breaking waves) as well as its spatial trends along the barred profile (under breaking waves). However, the model systematically overpredicts the wave boundary layer thickness under non-breaking waves (in $\approx 25 \%$ ).

In terms of turbulence simulations, the magnitudes of $\langle k\rangle$ are overestimated, which is a common issue for RANS models. However, the model adequately captures the spatial and temporal patterns including trends of the observed turbulence advection processes.

In terms of sediment transport dynamics, for the non-breaking waves cases, the simulated net transport rates are in good agreement with the measurements (within a factor 2 for all four combinations of wave and sand conditions). However, under breaking waves conditions, although some spatial (crossshore and vertical) distributions are captured, the model cannot reproduce the high concentrations in the wave breaking zone. Hence, the model supports the idea that wave breaking turbulence effects should be accounted for in suspended sediment pick-up or reference concentration formulations (Van der Zanden et al., 2017).

Despite some quantitative differences between the model and measurements, and taking into consideration that this is the first validation of this type of models in terms of wave boundary layer processes and sediment transport, it is concluded that the Jacobsen et al. (2014) and Jacobsen and Fredsøe (2014) morphodynamic RANS-VOF model is a valuable tool to further investigate hydrodynamic and sand transport processes over the full water column including the wave boundary layer. Further efforts will focus on improving the wave breaking location, on analyzing the overpredictions of the wave boundary layer thickness and turbulence in the shoaling zone, and on suspended and bed-load transport rates in relation to morphologic changes. 


\section{ACKNOWLEDGMENTS}

The research presented in this paper is part of the SINBAD project, funded by STW (12058) and EPSRC (EP/J00507X/1, EP/J005541/1). The data supporting the results in the present study will be available upon request (j.vanderzanden@utwente.nl) after the SINBAD project is completed.

\section{References}

T. Aagaard and S. G. Jensen. Sediment concentration and vertical mixing under breaking waves. Marine Geology, 336:146 - 159, 2013. ISSN 0025-3227. doi: http://dx.doi.org/10.1016/j.margeo.2012.11. 015 .

R. Bakhtyar, A. Yeganeh-Bakhtiary, D. Barry, and A. Ghaheri. Two-phase hydrodynamic and sediment transport modeling of wave-generated sheet flow. Advances in Water Resources, 32(8):1267 - 1283, 2009. ISSN 0309-1708. doi: http://dx.doi.org/10.1016/j.advwatres.2009.05.002.

J. A. Brinkkemper, A. T. M. de Bakker, and B. G. Ruessink. Intrawave sand suspension in the shoaling and surf zone of a field-scale laboratory beach. Journal of Geophysical Research: Earth Surface, 122(1):356-370, 2017. ISSN 2169-9011. doi: 10.1002/2016JF004061. 2016JF004061.

S. Brown, D. Greaves, V. Magar, and D. Conley. Evaluation of turbulence closure models under spilling and plunging breakers in the surf zone. Coastal Engineering, 114:177 - 193, 2016. ISSN 0378-3839. doi: http://dx.doi.org/10.1016/j.coastaleng.2016.04.002.

E. D. Christensen. Large eddy simulation of spilling and plunging breakers. Coastal Engineering, 53 (5-6):463 - 485, 2006. ISSN 0378-3839. doi: http://dx.doi.org/10.1016/j.coastaleng.2005.11.001.

E. D. Christensen, D.-J. Walstra, and N. Emerat. Vertical variation of the flow across the surf zone. Coastal Engineering, 45(3-4):169 - 198, 2002. ISSN 0378-3839. doi: http://dx.doi.org/10.1016/ S0378-3839(02)00033-9. Surface and Swash Zone Mechanics.

A. Davies, L. van Rijn, J. Damgaard, J. van de Graaff, and J. Ribberink. Intercomparison of research and practical sand transport models. Coastal Engineering, 46(1):1 - 23, 2002. ISSN 0378-3839. doi: http://dx.doi.org/10.1016/S0378-3839(02)00042-X.

M. Dyhr-Nielsen and T. Sørensen. Some sand transport phenomena on coasts with bars. Coastal Engineering Proceedings, 1(12):855-865, 1970.

F. Engelund and J. Fredsøe. A sediment transport model for straight alluvial channels. Hydrology Research, 7(5):293-306, 1976. ISSN 0029-1277.

J. Fredsøe and R. Deigaard. Mechanics of Coastal Sediment Transport. Advanced Series on Ocean Engineering. World Scientific, 1992. ISBN 9789810208417.

J. Fredsøe, B. Sumer, A. Kozakiewicz, L. H. Chua, and R. Deigaard. Effect of externally generated turbulence on wave boundary layer. Coastal Engineering, 49(3):155 - 183, 2003. ISSN 0378-3839. doi: http://dx.doi.org/10.1016/S0378-3839(03)00032-2.

F. Grasso, B. Castelle, and B. Ruessink. Turbulence dissipation under breaking waves and bores in a natural surf zone. Continental Shelf Research, 43:133 - 141, 2012. ISSN 0278-4343. doi: http: //dx.doi.org/10.1016/j.csr.2012.05.014.

W. Hassan and J. Ribberink. Modelling of sand transport under wave-generated sheet flows with a \{RANS \} diffusion model. Coastal Engineering, 57(1):19 - 29, 2010. ISSN 0378-3839. doi: http: //dx.doi.org/10.1016/j.coastaleng.2009.08.009.

L. E. Holmedal and D. Myrhaug. Boundary layer flow and net sediment transport beneath asymmetrical waves. Continental Shelf Research, 26(2):252 - 268, 2006. ISSN 0278-4343. doi: http://dx.doi.org/ 10.1016/j.csr.2005.11.004.

T.-J. Hsu and P. L.-F. Liu. Toward modeling turbulent suspension of sand in the nearshore. Journal of Geophysical Research: Oceans, 109(C6), 2004. ISSN 2156-2202. doi: 10.1029/2003JC002240. C06018. 
D. Hurther, P. D. Thorne, M. Bricault, U. Lemmin, and J.-M. Barnoud. A multi-frequency acoustic concentration and velocity profiler (ACVP) for boundary layer measurements of fine-scale flow and sediment transport processes. Coastal Engineering, 58(7):594 - 605, 2011. ISSN 0378-3839. doi: http://dx.doi.org/10.1016/j.coastaleng.2011.01.006. Scaling, Analysis and New instrumentation for Dynamic bed tests. The SANDS-Hydralab $\{$ III $\}$ papers.

N. G. Jacobsen and J. Fredsøe. Formation and development of a breaker bar under regular waves. Part 2: Sediment transport and morphology. Coastal Engineering, 88:55 - 68, 2014. ISSN 0378-3839. doi: http://dx.doi.org/10.1016/j.coastaleng.2014.01.015.

N. G. Jacobsen, D. R. Fuhrman, and J. Fredsøe. A wave generation toolbox for the open-source cfd library: Openfoam @. International Journal for Numerical Methods in Fluids, 70(9):1073-1088, 2012. ISSN 1097-0363. doi: 10.1002/fld.2726.

N. G. Jacobsen, J. Fredsøe, and J. H. Jensen. Formation and development of a breaker bar under regular waves. Part 1: Model description and hydrodynamics. Coastal Engineering, 88:182 - 193, 2014. ISSN 0378-3839. doi: http://dx.doi.org/10.1016/j.coastaleng.2013.12.008.

B. L. Jensen, B. M. Sumer, and J. Fredsøe. Turbulent oscillatory boundary layers at high reynolds numbers. Journal of Fluid Mechanics, 206:265-297, 09 1989. doi: 10.1017/S0022112089002302.

W. Kranenburg, J. Ribberink, J. Schretlen, and R. Uittenbogaard. Sand transport beneath waves: the role of progressive wave streaming and other free surface effects. Journal of geophysical research. Earth surface, 118(1):1 - 18, 2013.

F. R. Menter. Two-equation eddy-viscosity turbulence models for engineering applications. AIAA Journal, 32(8):1598-1605, 1994.

K. Nadaoka, S. Ueno, and T. Igarashi. Sediment suspension due to large scale eddies in the surf zone. Coastal Engineering Proceedings, 1(21), 2011. ISSN 2156-1028. doi: 10.9753/icce.v21.\%p.

W. Rodi. Turbulence models and their application in hydraulics : a state-of-the-art review. Rotterdam : Balkema, 3rd ed edition, 1993. ISBN 9054101504. Published for the International Association for Hydraulic Research.

A. Roulund, B. M. Sumer, J. Fredsøe, and J. Michelsen. Numerical and experimental investigation of flow and scour around a circular pile. Journal of Fluid Mechanics, 534:351-401, 7 2005. ISSN 1469-7645. doi: 10.1017/S0022112005004507.

B. G. Ruessink, H. Michallet, T. Abreu, F. Sancho, D. A. Van der A, J. J. Van der Werf, and P. A. Silva. Observations of velocities, sand concentrations, and fluxes under velocity-asymmetric oscillatory flows. Journal of Geophysical Research: Oceans, 116(C3), 2011. ISSN 2156-2202. doi: 10.1029/ 2010JC006443. C03004.

J. Schretlen. Sand transport under full-scale progressive surface waves. $\mathrm{PhD}$ thesis, University of Twente, Enschede, The Netherlands, 2012.

J. Schretlen, J. Ribberink, and T. O'Donoghue. Boundary layer flow and sand transport under full scale surface waves. In J. M. Amith and P. Lynett, editors, Proceedings 32nd ICCE 2010, Shangai, pages 1-14. CERC, 2011.

C. P. Scott, D. T. Cox, T. B. Maddux, and J. W. Long. Large-scale laboratory observations of turbulence on a fixed barred beach. Measurement Science and Technology, 16(10):1903, 2005.

B. Sumer, T. Laursen, and J. Fredsøe. Wave boundary layers in a convergent tunnel. Coastal Engineering, 20(3):317 - 342, 1993. ISSN 0378-3839. doi: http://dx.doi.org/10.1016/0378-3839(93) 90006- $\mathrm{T}$.

I. Svendsen, P. Madsen, and J. Hansen. Wave characteristics in the surf zone. Coastal Engineering Proceedings, 1(16), 1978. ISSN 2156-1028.

F. C. Ting and J. T. Kirby. Observation of undertow and turbulence in a laboratory surf zone. Coastal Engineering, 24(1-2):51 - 80, 1994. ISSN 0378-3839. doi: http://dx.doi.org/10.1016/0378-3839(94) 90026-4. 
A. Torres-Freyermuth, I. J. Losada, and J. L. Lara. Modeling of surf zone processes on a natural beach using reynolds-averaged navier-stokes equations. Journal of Geophysical Research: Oceans, 112 (C9):n/a-n/a, 2007. ISSN 2156-2202. doi: 10.1029/2006JC004050. C09014.

D. A. Van der A, J. van der Zanden, T. O’Donoghue, D. Hurther, I. Cáceres, S. J. McLelland, and J. S. Ribberink. Large-scale laboratory study of breaking wave hydrodynamics over a fixed bar. Journal of Geophysical Research: Oceans, pages n/a-n/a, 2017. ISSN 2169-9291. doi: 10.1002/ 2016JC012072.

J. Van der Zanden, D. A. Van der A, D. Hurther, I. Cáceres, T. O’Donoghue, and J. S. Ribberink. Nearbed hydrodynamics and turbulence below a large-scale plunging breaking wave over a mobile barred bed profile. Journal of Geophysical Research: Oceans, 121(8):6482-6506, 2016. ISSN 2169-9291. doi: $10.1002 / 2016 \mathrm{JC} 011909$.

J. Van der Zanden, D. A. Van der A, D. Hurther, I. Cáceres, T. O’Donoghue, and J. S. Ribberink. Suspended sediment transport around a large-scale laboratory breaker bar. Coastal Engineering, in press, 2017.

D. C. Wilcox. Reassessment of the scale-determining equation for advanced turbulence models. AIAA Journal, 26:1299-1310, Nov. 1988. doi: 10.2514/3.10041.

Z. Xie. Numerical study of breaking waves by a two-phase flow model. International Journal for Numerical Methods in Fluids, 70(2):246-268, 2012. ISSN 1097-0363. doi: 10.1002/fld.2690.

Z. Xie. Two-phase flow modelling of spilling and plunging breaking waves. Applied Mathematical Modelling, 37(6):3698 - 3713, 2013. ISSN 0307-904X. doi: http://dx.doi.org/10.1016/j.apm.2012. 07.057 .

H.-D. Yoon and D. T. Cox. Large-scale laboratory observations of wave breaking turbulence over an evolving beach. Journal of Geophysical Research: Oceans, 115(C10):n/a-n/a, 2010. ISSN 21562202. doi: 10.1029/2009JC005748. C10007.

H.-D. Yoon and D. T. Cox. Cross-shore variation of intermittent sediment suspension and turbulence induced by depth-limited wave breaking. Continental Shelf Research, 47:93 - 106, 2012. ISSN 0278-4343. doi: http://dx.doi.org/10.1016/j.csr.2012.07.001.

Q. Zhao, S. Armfield, and K. Tanimoto. Numerical simulation of breaking waves by a multi-scale turbulence model. Coastal Engineering, 51(1):53 - 80, 2004. ISSN 0378-3839. doi: http://dx.doi. org/10.1016/j.coastaleng.2003.12.002.

Z. Zhou, T.-J. Hsu, D. Cox, and X. Liu. Large-eddy simulation of wave-breaking induced turbulent coherent structures and suspended sediment transport on a barred beach. Journal of Geophysical Research: Oceans, 122(1):207-235, 2017. ISSN 2169-9291. doi: 10.1002/2016JC011884.

J. A. Zyserman and J. Fredsøe. Data analysis of bed concentration of suspended sediment. Journal of Hydraulic Engineering, 120(9):1021-1042, 1994. doi: 10.1061/(ASCE)0733-9429(1994)120: 9(1021). 